Article

\title{
Synthesis and Comparative Biological Properties of Ag-PEG Nanoparticles with Tunable Morphologies from Janus to Multi-Core Shell Structure
}

\author{
Mengda Xu ${ }^{1}$, Jie Liu ${ }^{1}$, Xiankui Xu ${ }^{1}$, Shanhu Liu ${ }^{1}$, František Peterka ${ }^{2}$, Yanrong Ren ${ }^{1, *(1)}$ \\ and Xianfeng $\mathrm{Zhu}^{3, *}$ \\ 1 Henan Engineering Laboratory of Flame-retardant and Functional Materials, Institute of Functional Polymer \\ Composites, College of Chemistry and Chemical Engineering, Henan University, Kaifeng 475004, China; \\ 104753150813@vip.henu.edu.cn (M.X.); 104753160807@vip.henu.edu.cn (J.L.); \\ 104753170806@vip.henu.edu.cn (X.X.); liushanhu@henu.edu.cn (S.L.) \\ 2 Technical University of Liberec, Studentská 1402/2 461 17, Liberec 46117, Czech Republic; fpet@volny.cz \\ 3 School of Life Sciences, Henan University, Kaifeng 475004, China \\ * Correspondence: renyr@henu.edu.cn (Y.R.); xianfengzhu@henu.edu.cn (X.Z.); Tel.: +86-371-23881586 (Y.R.)
}

Received: 16 August 2018; Accepted: 17 September 2018; Published: 20 September 2018

\begin{abstract}
Silver nanoparticles synthesized with polymers as coating agents is an effective method to overcome their poor stability and aggregation in solution. Silver-polyethylene glycol (Ag-PEG) nanoparticles were synthesized with the thiol-functionalized polyethylene glycol (SH-PEA) as the coating, reducing and stabilizing agent. The UV irradiation time, polymer and silver nitrate concentration for the synthesis were investigated. The concentration of silver nitrate had significant effect on the morphology of Ag-PEG nanoparticles. When increasing the concentration of silver nitrate, SEM and TEM images showed that Ag-PEG nanoparticles changed from Janus to multi-core shell structure. Meanwhile, pure silver particles in the two hybrid nanoparticles presented spherical shape and had the similar size of $15 \mathrm{~nm}$. The antibacterial activities and cytotoxicity of the two structural Ag-PEG nanoparticles were investigated to understand colloid morphology effect on the properties of AgNPs. The results of antibacterial activities showed that the two structural Ag-PEG nanoparticles exhibited strong antibacterial activities against Staphylococcus aureus, Escherichia coli and Bacillus subtilis. The Janus nanoparticles had larger minimal inhibitory concentration (MIC) and minimum bacterial concentration $(\mathrm{MBC})$ values than the multi-core shell counterparts. The results of cytotoxicity showed the Janus Ag-PEG nanoparticles had lower toxicity than the multi-core shell nanoparticles.
\end{abstract}

Keywords: silver nanoparticle; PEG; Janus nanoparticle; muli-core shell nanoparticle; antibacterial activity; cytotoxicity

\section{Introduction}

Silver nanoparticles (AgNPs) have attracted increasing interest due to their unique physical, chemical and biological properties, including surface-enhanced Raman scattering, catalytic activity, non-linear optical behavior and broad-spectrum bactericidal activity [1-9]. Many methods have been reported for the synthesis of AgNPs with chemical, physical, photochemical and biological routes with tunable size and shape [10-15]. However, AgNPs have high surface area, resulting in poor colloidal stability and aggregation in solution. Stabilizing/capping agents have been utilized in the synthesis process of AgNPs to overcome this instability [16-18]. Among these agents, polymers are effective agents to form an outer shell coating to the silver cores or a carrier to loading AgNPs on their surface, providing a steric barrier to aggregation [19-22]. Furthermore, studies have been found that the concentration or the types of polymers have some effect on the size, shape and properties 
of AgNPs [11,18], while the effect of the morphology of Ag-polymer hybrids on their properties has rarely been concerned.

Janus particles possess two or more different chemical components and spatial distribution that have different surface, structures or material properties [23,24]. Although Janus nanoparticles combine individual components together, their properties are not interfered with or completely lost, which makes them a unique category of materials compared to conventional nanoparticles $[25,26]$. In comparison with the other noble metals, silver has gained less interest in the fabrication of Janus particles. Some silver-gold bimetal or silver-sillica Janus nanoparticles have been prepare by depositing growth on the metal seeds [27-30]. Chen et al. [27] had compared a Janus Au@Ag nanoparitlces to their Au@Ag and Ag@Au core-shell counterparts, and found that the Janus nanoparticles exhibited enhanced electrocatalytic activity in oxygen reduction reactions. They explained the result may be caused by the partial charge transfer from Au to Ag that optimized the oxygen absorption on the metal surfaces which was affected by the interfaces between $\mathrm{Au}$ and Ag. This research has illustrated that the properties of metal nanoparticles can be improved by varying their morphology. Up to date, few silver-polymer Janus nanoparticles have been studied in spite of the wide synthesis and application of silver-polymer hybrids.

In this paper, we present a facile and fast approach for the fabrication of silver-polyethylene glycol (Ag-PEG) nanoparticles with tunable morphologies in Janus and multi-core shell structure which was performed by photochemical reduction method with thiol-functionalized polyethylene glycol (SH-PEA) as the coating, reducing and stabilizing agent. Optimization of different experimental variables like UV irradiation time, polymer concentration and silver precursor concentration were systematically investigated for the two structures of Ag-PEG nanoparticles. Silver colloids are usually stable against auto-aggregation which is potential materials in antibacterial and anticancer medicine. Thus, the biological properties of Ag-PEG nanoparticles had been concerned about. To understand the effect of the morphology of the hybrid nanoparticles on their biological properties, the antibacterial activities and cytotoxicity of the Janus and multi-core shell Ag-PEG nanoparticles were assessed by bacterial growth inhibitory and 3-[4,5-dimethylthiazol-2-yl]-2,5-dephenyl tetrazolium bromide (MTT) cell viability assays, respectively.

\section{Materials and Methods}

\subsection{Materials}

Mercapto-ethylamine (MEA) was purchased from Xiya Reagent (Linshu, Shandong, China). Poly(ethylene glycol) diglycidyl ether (PEGDE, $M_{n}=500 \mathrm{~g} \cdot \mathrm{mol}^{-1}$ ) was obtained from Sigma-Aldrich Co. (Shanghai, China). Silver nitrate $\left(\mathrm{AgNO}_{3}\right)$, alcohol and $\mathrm{n}$-hexane were purchased from Tian Jin Chemical Reagent (Tianjin, China). 3-(4,5-dimethylthiazol-2-yl)-2,5-ziphenyl tetrazolium bromide (MTT) was purchased from Amresco Inc. (Solon, OH, USA). Dulbecco's modified eagle medium (DMEM) and fetal bovine serum (FBS) were obtained from Gibco BRL Co. (Gaithersburg, MD, USA). The phosphate buffer saline (PBS) was made in laboratory according to the literature [31]. Briefly, potassium chloride $(4 \mathrm{~g})$, potassium phosphate monobasic $(4 \mathrm{~g})$, sodium chloride $(160 \mathrm{~g})$, and sodium phosphate dibasic heptahydrate $(43.2 \mathrm{~g})$ were dissolved in $1 \mathrm{~L}$ deionized (DI) water. Staphylococcus aureus (ATCC 6358P), Escherichia coli (CGMCC 1.90) and Bacillus subtilis (CGMCC 1.1849) were used for the bacterial studies. All microorganisms were provided by China General Microbiological Culture Collection Center (CGMCC), Chinese Academy of Sciences (CAS), Beijing, China. The bacterial strains were grown in Luria-Bertani agar plates from Hopebiol (Qingdao, Shandong, China) at $37^{\circ} \mathrm{C}$.

\subsection{Measurement}

FT-IR spectra were recorded in a FT-IR SPECRUM VERTEX 70 spectrometer (Bruker, Ettlingen, Germany) on thoroughly dried samples by using $\mathrm{KBr}$ pellets. ${ }^{1} \mathrm{H}$ Nuclear Magnetic Resonance 
$\left({ }^{1} \mathrm{H}\right.$ NMR) spectra were collected on an AVANCE III HD $400 \mathrm{MHz}$ spectrometer (Bruker, Zurich, Switzerland) in $\mathrm{CDCl}_{3}$ at $25^{\circ} \mathrm{C}$. Gel permeation chromatography (GPC) measurements were conducted with a Waters 410 GPC (Waters, Milford, PA, USA) equipped with Waters Styragel column (HT4 + HT3) using $\mathrm{CDCl}_{3}$ as the eluent, the molecular weights were calibrated with polystyrene standards, and the flow rate was set at $1.0 \mathrm{~mL} \mathrm{~min}{ }^{-1}$ at $35^{\circ} \mathrm{C}$. UV-Vis absorption spectra were recorded by using a U4100 spectrophotometer (Hitachi, Shanghai, China) with the as-prepared silver colloidal solution. The surface morphology of samples was analyzed on a JSM-7610F (JEOL, Tokyo, Japan) scanning electron microscope (SEM) and the main elements were measured by energy-dispersive X-ray spectrometry (EDS) (JEOL, Tokyo, Japan). The samples on the silicon wafers were mounted rigidly to a copper specimen holder using a conductive adhesive. Transmission electron microscopy (TEM) studies were performed on a JEM-2100 electron microscope (JOEL, Tokyo, Japan) operating at an acceleration voltage of $100 \mathrm{KV}$. The nanoparticle solution was dropped on copper grids, and dried at room temperature. X-ray diffraction (XRD) was recorded on a D 8 Advance (Bruker, Karlsruhe, Germany). The samples were drop cast on glass slides, and dried at room temperature.

\subsection{Synthesis of Thiol-Functionalized Polyethylene Glycol (SH-PEA)}

SH-PEA was synthesized following the procedure conducted by Wen and coworkers [31]. A mixture of PEGDE $(0.001 \mathrm{~mol})$ and mercapto-ethylamine $(0.001 \mathrm{~mol})$ was dissolved by ethanol $(4 \mathrm{~mL})$ with nitrogen (Air Separation Group Co., Ltd., Kaifeng, Henan, China). The mixture was stirred for $12 \mathrm{~h}$ under refluxing. Then, the mixture was poured into n-hexane. After removing the supernatant, the product was collected and dried in vacuum oven (Bluepard Instrumets Co., Ltd., Shanghai, China) at $40{ }^{\circ} \mathrm{C}$. The synthesis process was described in Scheme 1 .

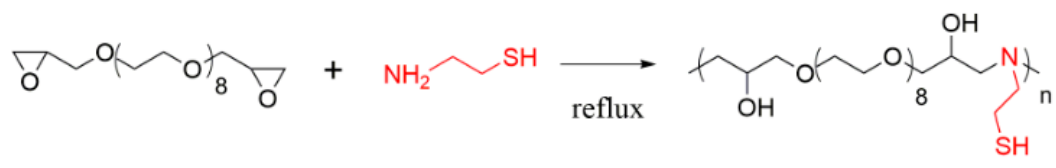

PEGDE

MEA

SH-PEA

Scheme 1. Schematic illustration of SH-PEG synthesis.

\subsection{Synthesis of Ag-PEG Nanoparticles}

The synthesis of Ag-PEG nanoparticles was carried out in a typical experiment. SH-PEA (20 mg) and $\mathrm{AgNO}_{3}(4 \mathrm{mg})$ were dissolved into $20 \mathrm{~mL}$ distilled water at room temperature. After $3 \mathrm{~h}$, the mixture solution was subjected to UV-irradiation with a UV light (UV LED Curing System, UP313, Uvata Precision Optoelectronics Co., Ltd., Shanghai, China) at an intensity of $75 \mathrm{~mW} \cdot \mathrm{cm}^{-2}$ at $365 \mathrm{~nm}$ for $3 \mathrm{~min}$. The reaction mixture was extensively dialyzed against water for 3 days to remove the excess reactants. The optimization of different experimental variables of UV irradiation time, SH-PEA concentration and silver nitrate concentration were investigated systematically.

\subsection{Antibacterial Properties of Ag-PEG Nanoparticles}

Oxford cup method was used to determine the antibacterial activity with different bacterial such as E. coli, S. aureus and B. subtilis according to the previous report [32]. The bacterial suspension $\left(10^{6} \mathrm{CFU}\right.$ $\mathrm{mL}^{-1}$ ) was inoculated evenly on a Luria-Bertani agar plate. Then, the Oxford cups were placed on the surfaces of the cultures, and an amount of $200 \mu \mathrm{L}$ solution of the nanoparticle $\left(1 \mathrm{mg} \mathrm{mL}^{-1}\right)$ was place into the oxford cups. After incubation for $24 \mathrm{~h}$ at $37^{\circ} \mathrm{C}$, the antibacterial activity was evaluated by measuring the average diameters of the zones of inhibition with a vernier calliper for three times.

The minimal inhibitory concentration (MIC) was read by the visual turbidity of the tubes noted before and after incubation according to previous reports [33,34]. The Ag-PEG nanoparticles were dissolved in a nutrent agar to prepare stock solutions $\left(4 \mathrm{mg} \mathrm{mL}^{-1}\right)$. Distinct volumes of the stock solutions were diluted by $10 \mathrm{~mL}$ growth medium to form series of solutions with different concentration 
of Ag-PEG nanoparticles. Then, these solutions were inoculated with $100 \mu \mathrm{L}$ of a bacterial suspension $\left(10^{5} \mathrm{CFU} \mathrm{mL} \mathrm{m}^{-1}\right)$ and then cultured for 1 day in a $37^{\circ} \mathrm{C}$ incubator and immediately used in MIC assays. To determine MIC, the cultures were analyzed for the absence of turbidity. A total of 3 replicates were carried out for each treatment and the corresponding controls.

The minimum bacterial concentration (MBC) was determined according to the previous report [35]. After the MIC determination of the Ag-PEG nanoparticles tested, an aliquot of $1 \mathrm{~mL}$ from each test tube in which no visible bacterial growth was observed was inoculated on Luria-Bertani agar and then incubated overnight at $37^{\circ} \mathrm{C}$. $\mathrm{MBC}$ is defined as the lowest concentration of antimicrobial agent that kill $>99 \%$ of the initial bacterial population, at which there is the lowest concentration of antimicrobial agent that on the plates have no bacterial growth. Each bacterium was assayed at least three times.

\subsection{Cytotoxicity}

The cytotoxicity of Ag-PEG was examined by MTT assay. All sample solutions were diluted with DMEM to obtain preset concentrations. HepG2 and MCF-7 cells were seeded into 96-well plates with a density of $10^{4}$ cells per well and incubated in DMEM $(100 \mathrm{~mL})$ for $24 \mathrm{~h}$. Then, seven concentrations $\left(250,125,64,32,6,8\right.$ and $\left.4 \mu \mathrm{g} \mathrm{mL}^{-1}\right)$ of Ag-PEG were added to the wells. Three parallel wells for each sample were used at a specific concentration. After co-incubation with cells for $48 \mathrm{~h}, 20 \mu \mathrm{L}$ of MTT solution in PBS $\left(5 \mathrm{mg} \mathrm{mL}^{-1}\right)$ was added to each well and the plate was incubated for another $4 \mathrm{~h}$ at $37^{\circ} \mathrm{C}$. After that, the medium containing MTT was removed, and $150 \mu \mathrm{L}$ of DMSO was added to each well to dissolve the MTT formazan crystals. Finally, the plates were shaken for $5 \mathrm{~min}$, and the absorbance of formazan product was measured at $490 \mathrm{~nm}$ by a Bio-Rad 680 micro-plate reader (Hercules, CA, USA).

\section{Results and Discussion}

\subsection{Characterization of the SH-PEA}

PEG is a hydrophilic polymer with excellent biocompatibility and widely used to modify metal or metal oxide nanomaterials for biomedicine application [36-38], which makes PEG the appropriate polymer for fabrication of AgNPs for the application in biological systems. The thiol-functionalized PEG was synthesized through nucleophilic-addition/ring-opening reaction between the epoxy groups of PEGDE and the amine group of MEA (Scheme 1). Nitrogen atoms were introduced into the macromolecular backbone after the reaction. The nitrogen-containing polymers have been successfully utilized as reducing and stabilizing agents in one-pot synthesis of AgNPs directly in aqueous solution without the aid of any other external agent $[39,40]$. Thus, it is interesting to use SH-PEA as the reducing and stabilizing agent for the fabrication of AgNPs due to the nitrogen atoms assisting silver ions reduction and the coordination of thiol groups to the surface as-formed AgNPs.

FT-IR and ${ }^{1} \mathrm{H}$ NMR spectra were used to study chemical structure of SH-PEA. SH-PEA has one characteristic absorption peak at $3396 \mathrm{~cm}^{-1}$, attributed to the stretching vibration of the -OH groups. The peaks at $2875 \mathrm{~cm}^{-1}$ belongs to the stretching vibration of $\mathrm{C}-\mathrm{H}$ bond (Figure 1a). The asymmetric stretching vibration of C-O-C of SH-PEA appears at $1106 \mathrm{~cm}^{-1} .{ }^{1} \mathrm{H}$ NMR spectrum of SH-PEA is shown in Figure $1 \mathrm{~b}$. The signals in the range of $2.4-2.8 \mathrm{ppm}$ are assigned to $-\mathrm{CH}_{2}$ - adjoining the ter-amino groups. The methylene and methine protons of the main chains give the signals at $3.4-4.1 \mathrm{ppm}$. Both FT-IR and ${ }^{1} \mathrm{H}$ NMR data confirm the structure of SH-PEA as proposed. GPC was utilized to determine the molecular weights $M_{\mathrm{n}}$ and polydispersity $\left(M_{\mathrm{w}} / M_{\mathrm{n}}\right)$. The data shows the $M_{\mathrm{n}}$ and polydispersity for SH-PEA is $0.67 \times 10^{4} \mathrm{~g} \mathrm{~mol}^{-1}$ and 2.41 . 
(a)

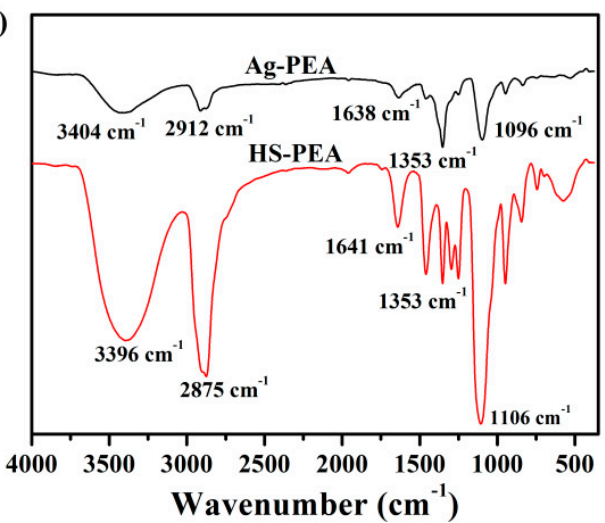

(b)

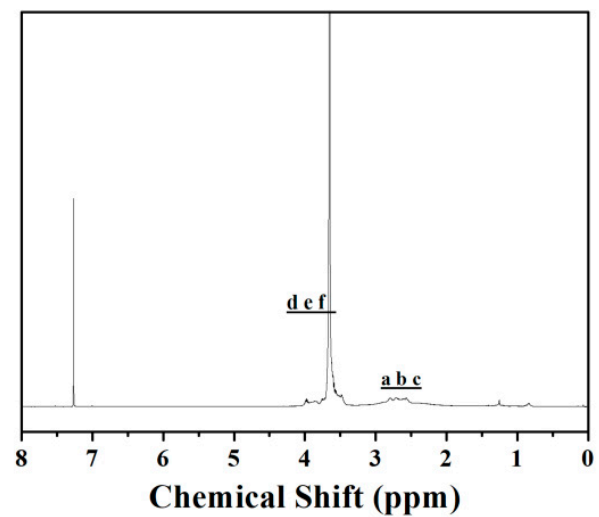

Figure 1. (a) FT-IR spectra of Ag-PEG nanoparticles and SH-PEA and (b) ${ }^{1} \mathrm{H}$ NMR spectrum of SH-PEA.

\subsection{Synthesis of Ag-PEG Nanoparticles}

The functionality of SH-PEA makes it possible to utilizing photochemical reduction route for the fabrication of AgNPs with a green and facile method. Photochemical reduction has been proved as a cost-effective, convenient and controllable technique to prepare AgNPs [41-43]. In this work, Ag-PEG nanoparticles were prepared through photochemical reduction of $\mathrm{AgNO}_{3}$ with SH-PEA in water.

The formation of Ag-PEG nanoparticles was confirmed by FT-IR spectroscopy. As shown in Figure 1a, the spectra of the Ag-PEG nanoparticles exhibit a few differences from that of SH-PEA. The peaks at $1641 \mathrm{~cm}^{-1}$, corresponding to the stretching peaks of tert-amine, shifts to $1638 \mathrm{~cm}^{-1}$ with a significant decrease in the transmittance. Meanwhile, the intensity of the C-S stretching band around $656 \mathrm{~cm}^{-1}$ almost disappears in the spectrum of Ag-PEG nanoparticles.

The optical properties of Ag-PEG nanoparticles were investigated using UV-Vis spectrometry. Figure 2 shows the UV-Vis absorption spectra of photochemical reduced products of a mixture of $0.2 \mathrm{mg}$ $\mathrm{mL}^{-1} \mathrm{AgNO}_{3}$ and $1 \mathrm{mg} \mathrm{mL}^{-1}$ SH-PEA at different time. It is obvious that no AgNPs formed without UV irradiation, even though the aqueous solution of SH-PEA and $\mathrm{AgNO}_{3}$ was stirred in dark for $3 \mathrm{~h}$. However, the color of the solution changed from colorless to brown when the solution was irradiated for several minutes, indicating the reduction of silver ion to silver and the formation of AgNPs. An absorption band was existed at $414 \mathrm{~nm}$ after irradiation for $1 \mathrm{~min}$, and the absorbance increases with increasing irradiation time. A single symmetric band with one maximum around $400 \mathrm{~nm}$ for the surface Plasmon resonance are attributed to the typical absorption spectrum of spherical AgNPs [44]. Although the nanoparticles irradiated for $5 \mathrm{~min}$ had the highest absorbance, the aggregation of the nanoparticles is serious and visible precipitation gathered at the bottom of the colloid solution. Thus, the irradiation time of $3 \mathrm{~min}$ is accepted for the other experiments for stable Ag-PEG nanoparticles.

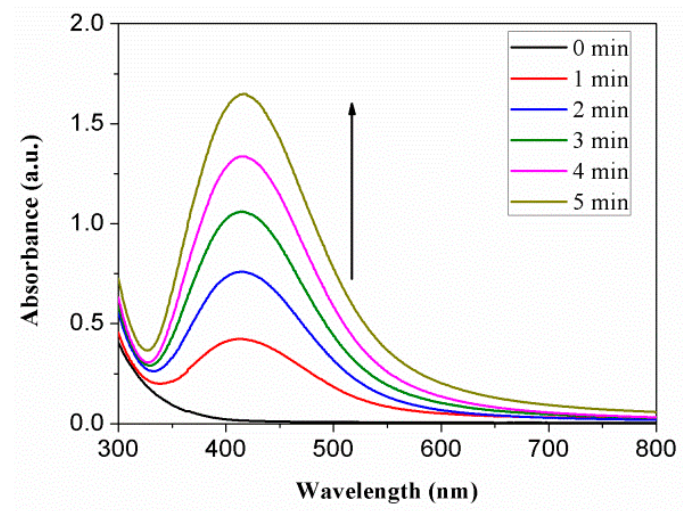

Figure 2. UV-Vis absorption spectra of Ag-PEG nanoparticles with different irradiation time. 
The morphologies and corresponding silver domain size distributions of Ag-PEG nanoparticles observed by using SEM and TEM are shown in Figure 3. The spherical AgNPs were ensured by SEM and TEM analysis. SEM image (Figure 3a) encloses a Janus structure with uniform dispersing which has about $38 \pm 18 \mathrm{~nm}$ bright silver due to a strong electron scattering signal and around $100 \mathrm{~nm}$ darkened PEG domain. TEM image (Figure 3c) is a little different from SEM image, which shows the Janus nanoparticles have black spherical silver domains with the size about $13 \pm 7 \mathrm{~nm}$ and grey PEG domains with the size about $15 \mathrm{~nm}$. The difference size of PEG domains in SEM and TEM images may caused by the quickly drying process of TEM sample by using the filter paper remove the excess water of the sample. Both of the images illustrate the asymmetric nanoparticles disperse uniformly in water without agglomeration. EDS image explains the nanoparticles contain Ag, C, N, O and S elements, matching the components of as-synthesized Ag-PEG nanoparticles (Figure 3e). The XRD pattern of Ag-PEG nanoparticles is shown in Figure 3f. The broad peak with $2 \theta$ around $25.5^{\circ}$ is related to the diffraction of amorphous SH-PEA, while the AgNPs show weak peaks at $2 \theta=38.4^{\circ}$ and $43.2^{\circ}$ index to (111) and (200) planes of Ag.
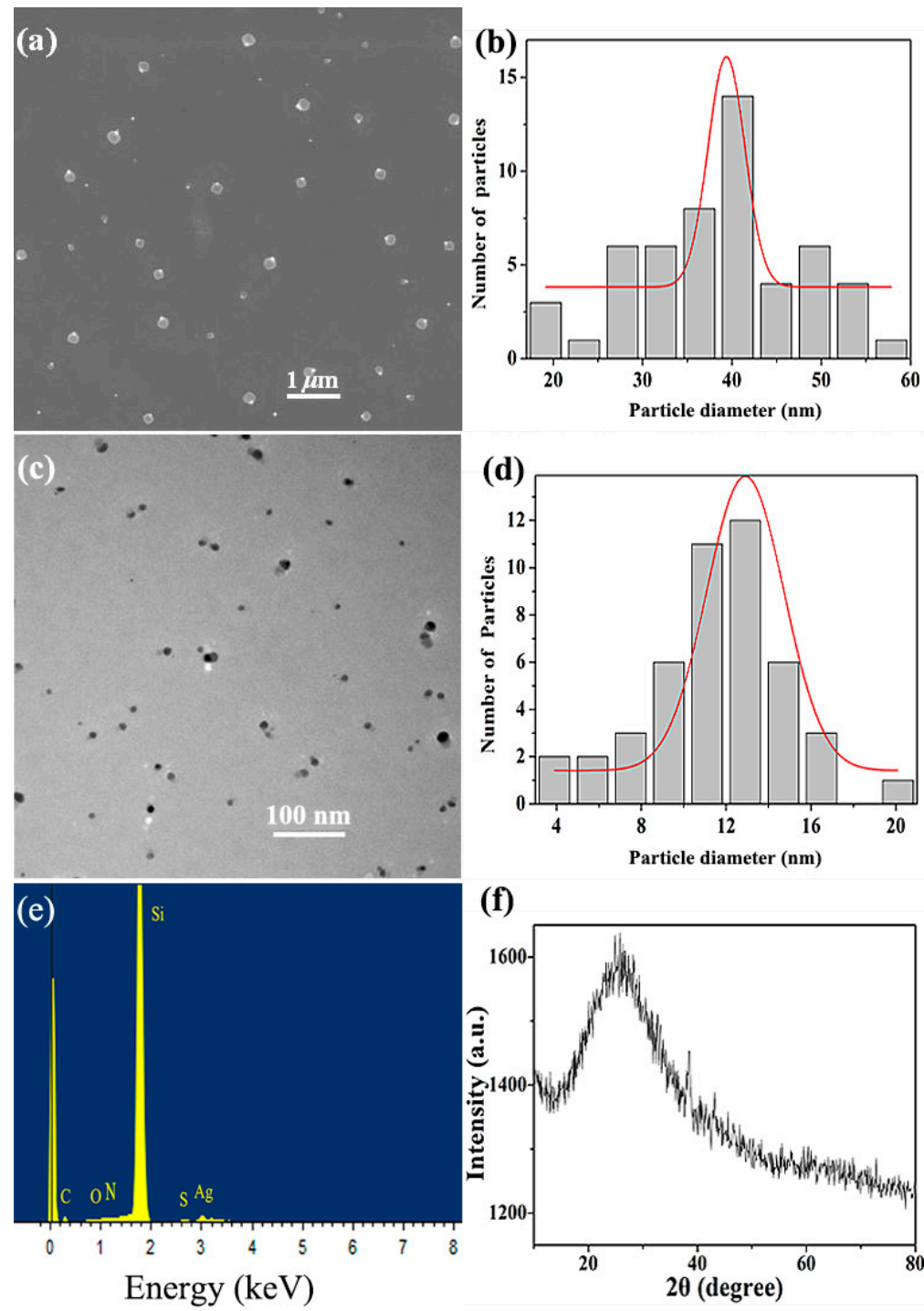

Figure 3. (a) SEM and (c) TEM images, (b,d) particles size distribution histograms from SEM and TEM images, (e) EDS image and (f) XRD pattern of Ag-PEG nanoparticles synthesized with $0.2 \mathrm{mg} \mathrm{mL}^{-1}$ $\mathrm{AgNO}_{3}, 1 \mathrm{mg} \mathrm{mL}^{-1} \mathrm{SH}-\mathrm{PEA}$ and 3 min irradiation. 
To investigate the influence of SH-PEA concentration on the size of AgNPs, we synthesized Ag-PEG nanoparticles with different SH-PEA concentration and $0.2 \mathrm{mg} \mathrm{mL}^{-1} \mathrm{AgNO}_{3}$, and monitored their surface Plasmon resonance with a UV-Vis spectrometer. In Figure 4a, the surface Plasmon resonance shows a band with a maximum at $414 \mathrm{~nm}$ for the concentration of SH-PEA increasing from 0.5 to $1.5 \mathrm{mg} \mathrm{mL}^{-1}$. Furthermore, increasing SH-PEA concentration, the band turns broader and takes a red shift to $428 \mathrm{~nm}$, which indicated that the AgNPs grow up or aggregate. Figure $4 \mathrm{~b}$ shows the TEM image of Ag-PEG nanoparticles synthesized with $2.5 \mathrm{mg} \mathrm{mL}^{-1}$ SH-PEA. Large Ag-PEG nanoparticles and agglomeration are observed, and the size of pure AgNPs is over $50 \mathrm{~nm}$, much larger than the size of Ag-PEG nanoparticles synthesized with $0.2 \mathrm{mg} \mathrm{mL}^{-1}$ SH-PEA. Besides, both Ag and PEG domains become irregular although the nanoparticles remain Janus structure. It is obvious that the lower SH-PEA concentration is appropriate for the stable Ag-PEG nanoparticles.
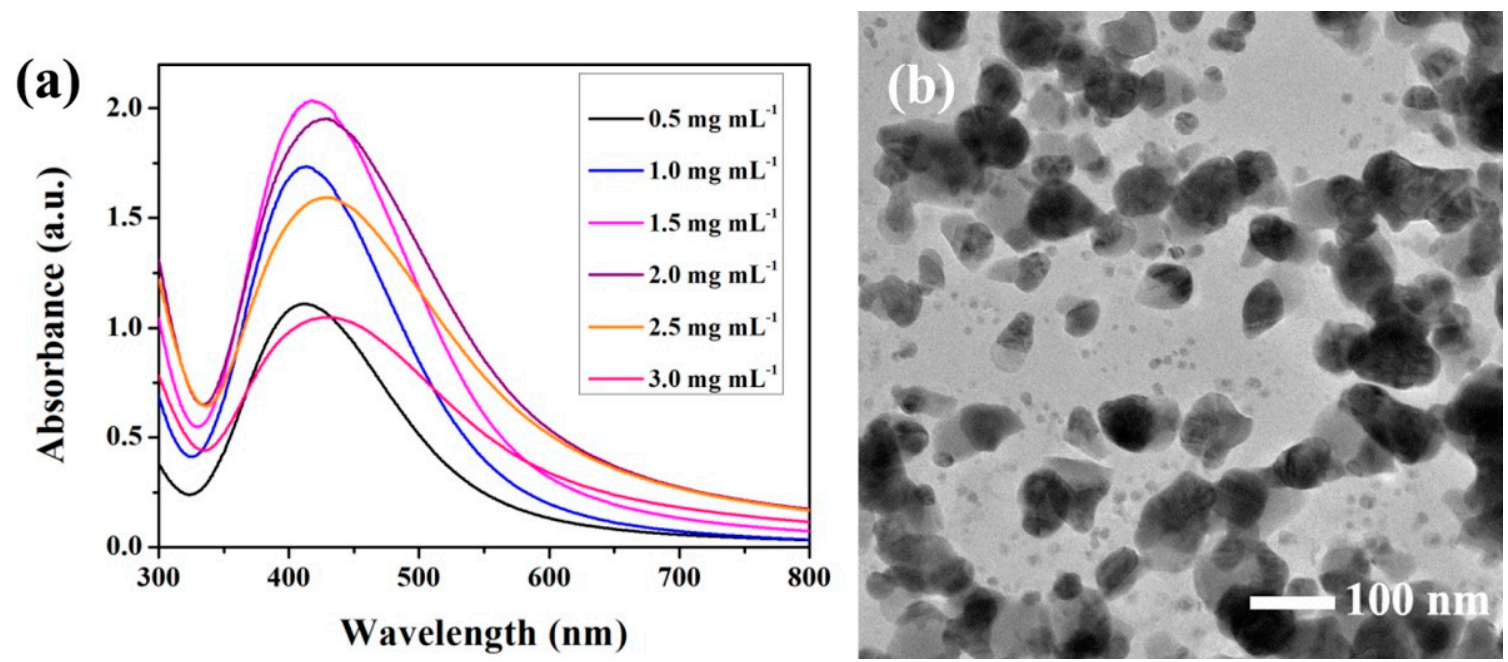

Figure 4. (a) Absorption spectra of Ag-PEG nanoparticles with different SH-PEA concentration; (b) TEM image of Ag-PEG nanoparticles synthesized with $2.5 \mathrm{mg} \mathrm{mL}^{-1} \mathrm{SH}-\mathrm{PEA}$ and $0.2 \mathrm{mg} \mathrm{mL}^{-1}$ $\mathrm{AgNO}_{3}$.

$\mathrm{AgNO}_{3}$ used as the precursor is an important variable in the synthesis of AgNPs. However, few researches have studied the effect of silver ion on the size, shape or properties of AgNPs. In this synthesis process, we found that the concentration of $\mathrm{AgNO}_{3}$ played a key role in the morphology of Ag-PEG nanoparticles. Figure 5 shows the morphological transformation with varying $\mathrm{AgNO}_{3}$ concentration from 0.2 to $1 \mathrm{mg} \mathrm{mL}^{-1}$. Figure 5a,d are the SEM and TEM images of the nanoparticles synthesized with $0.3 \mathrm{mg} \mathrm{mL}^{-1} \mathrm{AgNO}_{3}$, respectively. They are very similar as the result of Ag-PEG nanoparticles with $0.2 \mathrm{mg} \mathrm{mL}^{-1} \mathrm{AgNO}_{3}$ shown in Figure 3, except for the larger Ag domains with the size about $25 \mathrm{~nm}$. As $\mathrm{AgNO}_{3}$ concentration is $0.5 \mathrm{mg} \mathrm{mL}^{-1}$, a multi-core shell structure nanoparticles with the size about $100 \mathrm{~nm}$ exists in the image as shown in Figure 5b. It corresponding TEM image (Figure 5e) enclosed the multi-core shell structure may caused by the agglomeration of the Janus nanoparticles. Figure 5 b,e both present the multi-core shell structure coexists with the Janus structure, and the size of $\mathrm{Ag}$ domain further increases to $40 \mathrm{~nm}$. As $\mathrm{AgNO}_{3}$ concentration is up to $1.0 \mathrm{mg} \mathrm{mL}^{-1}$, the Janus nanoparticles almost disappear, and they are replaced by the multi-core shell nanoparticles (Figure 5c,f). The size of the multi-core shell nanoparticles is around $60 \mathrm{~nm}$, and the size of Ag cores returns to $15 \mathrm{~nm}$. According to the above results and discussion, it is concluded that the lower $\mathrm{AgNO}_{3}$ concentration is acceptable for Janus Ag-PEG nanoparticles and the higher $\mathrm{AgNO}_{3}$ concentration is appropriate for multi-core shell nanoparticles. 


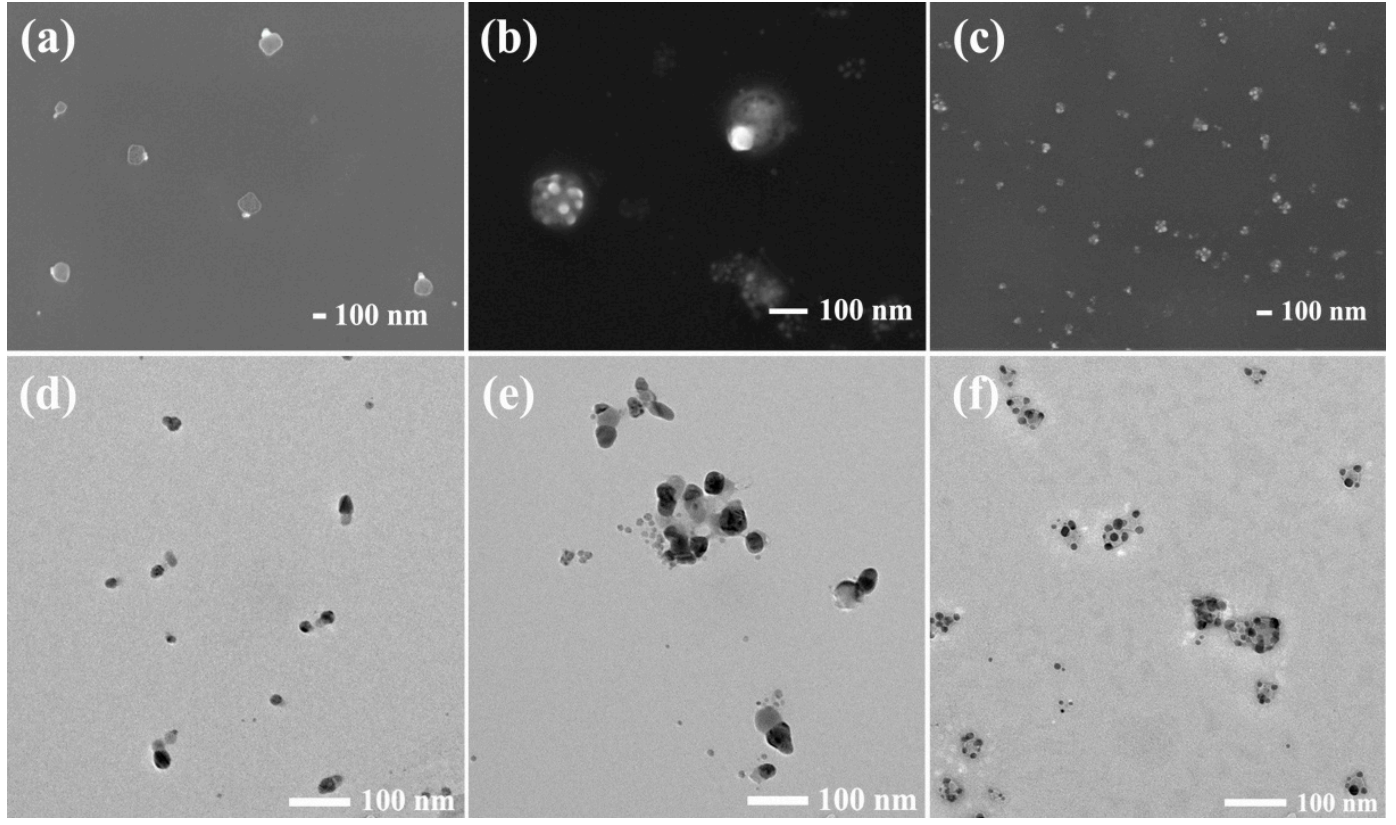

Figure 5. SEM images of Ag-PEG nanoparticles with (a) 0.3 , (b) 0.5 and (c) $1.0 \mathrm{mg} \mathrm{mL}^{-1} \mathrm{AgNO}_{3}$ concentration; TEM images of Ag-PEG nanoparticles with (d) 0.3 , (e) 0.5 and (f) $1.0 \mathrm{mg} \mathrm{mL}^{-1}$ $\mathrm{AgNO}_{3}$ concentration.

Although the significant change had taken place in the morphology of Ag-PEG nanoparticles as varying $\mathrm{AgNO}_{3}$ concentration, their UV-Vis absorption spectra still present a single band with a maximum around $414 \mathrm{~nm}$ (Figure 6). Since the single band is relative to the surface Plasmon resonance of spherical AgNPs, the shape of Ag domains ought to keep spherical shape as increasing $\mathrm{AgNO}_{3}$ concentration from 0.2 to $1.0 \mathrm{mg} \mathrm{mL}^{-1}$. The UV-Vis spectra, SEM and TEM image all explain the shape of the pure AgNPs remains unchanged when the morphology of Ag-PEA transforms.

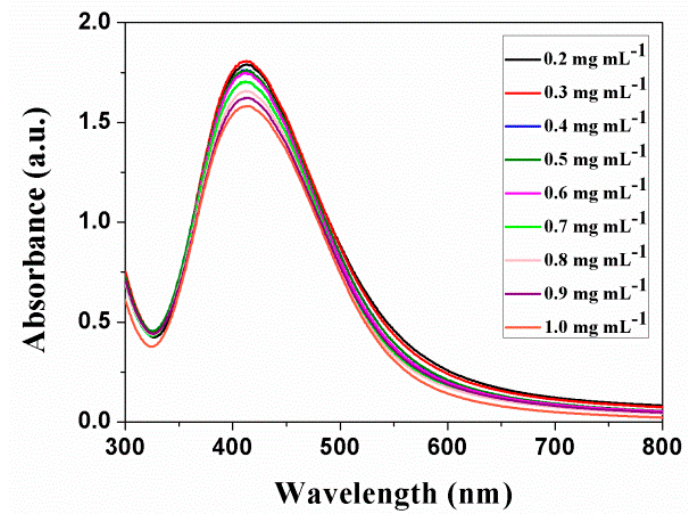

Figure 6. UV-Vis absorption spectra of Ag-PEG nanoparticles with different $\mathrm{AgNO}_{3}$ concentration.

\subsection{Antibacterial Activity}

AgNPs not only have broad spectrum antibactericidal and fungicidal activity [1,2], but also show high toxicity to animal species and cultured cells [45]. Studies have found that the biological effect of AgNPs depend on their size, shape and surface coating [46,47]. In this work, we were more interested in the morphological effect of Ag-PEG nanoparticles on their biological effect. For the biological properties test, the Janus nanoparticles were synthesized with $0.2 \mathrm{mg} \mathrm{mL}^{-1} \mathrm{AgNO}_{3}$ and $1 \mathrm{mg} \mathrm{mL}^{-1}$ SH-PEA, and the multi-core shell nanoparticles were with $1 \mathrm{mg} \mathrm{mL}^{-1} \mathrm{AgNO}_{3}$ and $1 \mathrm{mg} \mathrm{mL}^{-1} \mathrm{SH}-\mathrm{PEA}$. 
The antibacterial activity of SH-PEA and the Ag-PEG nanoparticles was evaluated by using bacterial growth inhibitory assay. Three bacteria were used to test the capability of different morphologies of Ag-PEG nanoparticles. One is Gram positive bacterium of $S$. aureus, the others are Gram negative bacteria of E. coli and B. subtilis. After incubated for $24 \mathrm{~h}$ at $37^{\circ} \mathrm{C}$, bacteria were still around the Oxford cups, which indicated SH-PEA did not have any antibacterial activity against the three bacteria. In Figure 7a-f, areas of clear media surround the Oxford cups filled with the solution of Janus or multi-core shell Ag-PEG nanoparticles. The average diameter of the zones of inhibition of the multi-core shell Ag-PEG nanoparticles are $14.67 \pm 2.19,14.05 \pm 0.65$ and $15.90 \pm 2.37 \mathrm{~mm}$ against $E$. coli, S. aureus and B. subtilis, respectively as shown in Figure 7h. And the values of the Janus Ag-PEG nanoparticles are $18.96 \pm 2.50,18.42 \pm 1.73$ and $18.52 \pm 1.99 \mathrm{~mm}$, respectively. The results demonstrate the two structure Ag-PEG nanoparticles have strong antibacterial activities to inhibit the growth of the three bacteria, and each structural nanoparticles perform even activities. Moreover, the Janus Ag-PEG nanoparticles perform better antibacterial activity than the multi-core shell ones. It should be noted that the pure silver amount of the Janus samples is much less than that of the multi-core shell ones. Since the shape and size of the pure AgNPs are same, the result must be caused by the difference between their morphologies.
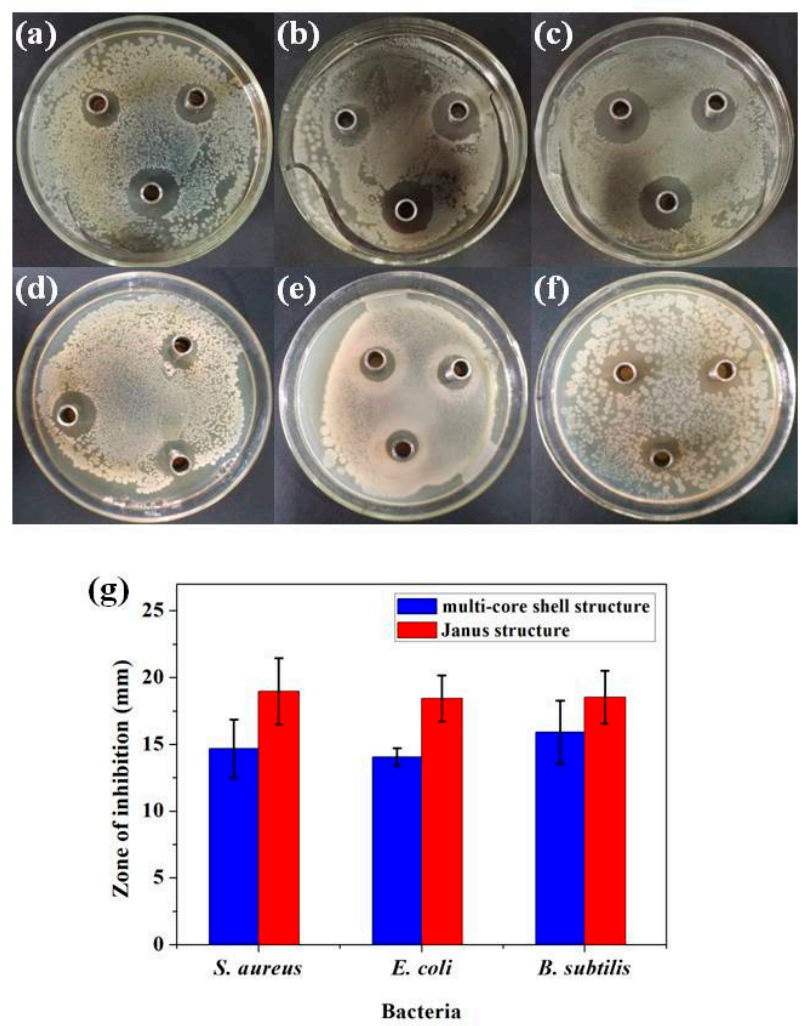

Figure 7. Inhibition Zones of the Janus $(\mathbf{a}-\mathbf{c})$ and multi-core shell Ag-PEG nanoparticles (d-f) against S. aureus $(\mathbf{a}, \mathbf{d})$, E. coli $(\mathbf{b}, \mathbf{e})$ and B. subtilis $(\mathbf{c}, \mathbf{f}) ;(\mathbf{g})$ the diameter of the inhibition zone of Ag-PEG nanoparticles.

A large decrease in the optical absorbance of the bacterial suspensions was observed when they were exposed to Ag-PEG nanoparticles. As shown in Table 1, the minimal inhibitory concentration (MIC) values of Janus Ag-PEG nanoparticles were 64,32 and $64 \mu \mathrm{g} \mathrm{mL}^{-1}$ against S. aureus, E. coli and $B$. subtilis, respectively. The values of multi-core shell nanoparticles were all $16 \mu \mathrm{g} \mathrm{mL}^{-1}$ against the three bacteria. The minimum bacterial concentration (MBC) values of the Janus nanoparticles were much higher than that of the multi-core shell nanoparticles. The MBC values of Janus Ag-PEG nanoparticles were $500 \mu \mathrm{g} \mathrm{mL} L^{-1}$ against $S$. aureus and E. coli, and $250 \mu \mathrm{g} \mathrm{mL}^{-1}$ against B. subtilis, while the values of multi-core shell nanoparticles were $64 \mu \mathrm{g} \mathrm{mL}{ }^{-1}$ against $S$. aureus and $32 \mu \mathrm{g} \mathrm{mL}^{-1}$ against 
E. coli and B. subtilis. The MBC/MIC ratio shows the two structural nanoparticles have different antibacterial properties. The ratio of the Janus Ag-PEG nanoparticles is higher than 4, suggesting that the Janus Ag-PEG can be considered as a bacteriostatic agent. On the contrary, the multi-core shell Ag-PEG nanoparticles have lower MBC/MIC ratio ( $\leq 4)$, performing with bactericidal manner [33].

Table 1. The minimal inhibitory concentration (MIC) and minimum bacterial concentration (MBC) of Ag-PEG nanoparticles against S. aureus, E. coli and B. subtilis.

\begin{tabular}{|c|c|c|c|c|c|c|}
\hline \multirow{2}{*}{ Bacterial Strain } & \multicolumn{3}{|c|}{ Janus Structure $\left(\mu \mathrm{g} \mathrm{mL}^{-1}\right)$} & \multicolumn{3}{|c|}{ Multi-Core Shell Structure $\left(\mu \mathrm{g} \mathrm{mL}^{-1}\right)$} \\
\hline & MIC & MBC & MBC/MIC Ratio & MIC & MBC & MBC/MIC Ratio \\
\hline S. aureus & 64 & 500 & 8 & 16 & 64 & 4 \\
\hline E. coli & 32 & 500 & 16 & 16 & 32 & 2 \\
\hline B. subtilis & 64 & 250 & 4 & 16 & 32 & 2 \\
\hline
\end{tabular}

\subsection{Cytotoxicity}

MTT assay was used to evaluate the cytotoxicity of Ag-PEG nanoparticles by using HepG2 and MCF-7 cell lines, and the results were shown in Figure 8. After incubating in all cell lines for $48 \mathrm{~h}$, the data clearly demonstrate that the pure SH-PEA is not cytotoxic at least up to the highest concentration evaluated $\left(500 \mu \mathrm{g} \mathrm{mL}^{-1}\right)$. The percentage of viable cells is always higher than $80 \%$. The Janus Ag-PEG nanoparticles tested in different concentrations in the range of $4-250 \mu \mathrm{g} \mathrm{mL}^{-1}$ shows a high percentage (around $90 \%$ ) of survival cells as its concentration is below $64 \mu \mathrm{g} \mathrm{mL}^{-1}$. Subsequently, a significant drop happens in their number for higher concentrations, and the drop of MCF-7 does faster. Instead, the multi-core shell Ag-PEG nanoparticles showed very high toxicity to HepG2 and MCF-7 cells. The percentage of viable cells for the multi-core shell nanoparticles against HepG2 is lower than $10 \%$ when its concentration is excess over $8 \mu \mathrm{g} \mathrm{mL}^{-1}$. To MCF-7, the number is only $81 \%$ even though the concentration of the nanoparticles is as low as $4 \mu \mathrm{g} \mathrm{mL}^{-1}$. The result demonstrates that the Janus Ag-PEG nanoparticles are more biocompatible than the multi-core shell with the investigated cells.
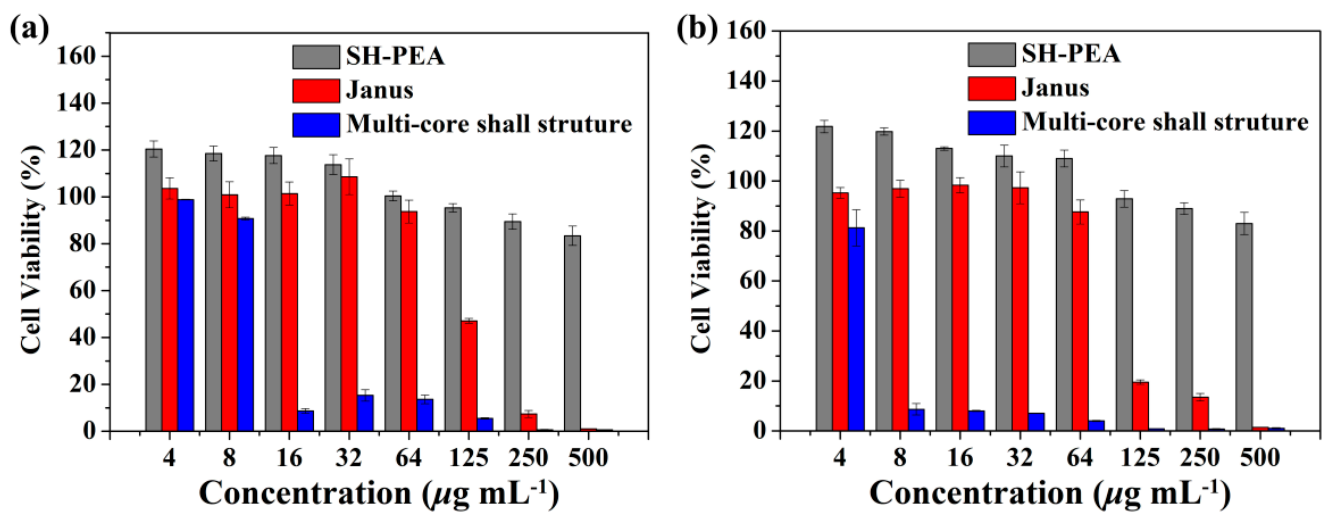

Figure 8. The cytotoxicity of SH-PEA and Ag-PEG nanoparticles against (a) HepG2 and (b) MCF-7 cells at different levels of concentration after $48 \mathrm{~h}$ incubation. Data were presented as mean \pm standard deviation $(n=3)$.

\section{Conclusions}

In summary, we synthesized Ag-PEG hybrid nanoparticles by photochemical reduction method with the as-synthesized SH-PEA as the coating, reducing and stabilizing agent. The condition of 3 min irradiation and $1 \mathrm{mg} \mathrm{mL}^{-1}$ SH-PEA is optimized for synthesizing stable Ag-PEG nanoparticles. The $\mathrm{AgNO}_{3}$ concentration plays a key role in tuning the morphologies of Ag-PEG nanoparticles. Janus Ag-PEG nanoparticles were synthesized with lower $\mathrm{AgNO}_{3}$ concentration, and multi-core shell structure with higher $\mathrm{AgNO}_{3}$ concentration. The pure AgNPs show spherical shape and have the 
size about $15 \mathrm{~nm}$ in the two structural Ag-PEG nanoparticles. Both structural Ag-PEG nanoparticles present strong antibacterial activities against $E$. coli, S. aureus and B. subtilis. The MIC and MBC values of the Janus nanoparticles are larger than those of the multi-core shell ones. The MBC/MIC ratio of the former is higher than 4, while the latter is lower than 4. HepG2 and MCF-7 cells were used to evaluate the cytotoxicity of the Ag-PEG nanoparticles. The Janus Ag-PEG nanoparticles show good biocompatibility when its concentration is below $64 \mu \mathrm{g} \mathrm{mL}^{-1}$, while the multi-core shell nanoparticles perform high toxicity even its concentration is as low as $8 \mu \mathrm{g} \mathrm{mL}^{-1}$. The results demonstrate the morphology of Ag-PEG hybrid nanoparticle has important effect on its biological properties.

Author Contributions: Conceptualization, Y.R.; Investigation, M.X., J.L., and X.X.; Data curation, S.L., Y.R. and X.Z.; Writing-original draft, review \& editing, Y.R. and F.P.

Funding: This research was funded by Developing Program of Natural Science of Henan province [No.172102410028].

Acknowledgments: Shiyong Song is acknowledged for his help in the cytotoxicity assay.

Conflicts of Interest: The authors declare no conflict of interest.

\section{References}

1. Marambio-Jones, C.; Hoek, E. A review of the antibacterial effects of silver nanomaterials and potential implications for human health and the environment. J. Nanopart. Res. 2010, 12, 1531-1551. [CrossRef]

2. Arvizo, R.R.; Bhattacharyya, S.; Kudgus, R.A.; Giri, K.; Bhattacharya, R.; Mukherjee, P. Intrinsic therapeutic applications of noble metal nanoparticles: Past, present and future. Chem. Soc. Rev. 2012, 41, 2943-2970. [CrossRef] [PubMed]

3. Xia, X.; Zeng, J.; McDearmon, B.; Zheng, Y.; Li, Q.; Xia, Y. Silver nanocrystals with concave surfaces and their optical and surface-enhanced raman scattering properties. Angew. Chem. Int. Ed. 2011, 50, 12542-12546. [CrossRef] [PubMed]

4. Yang, L.; Chen, Y.; Li, H.; Luo, L.; Zhao, Y.; Zhang, H.; Tian, Y. Application of silver nanoparticles decorated with $\beta$-cyclodextrin in determination of 6-mercaptopurine by surface-enhanced Raman spectroscopy. Anal. Methods 2015, 7, 6520-6527. [CrossRef]

5. Yang, K.H.; Chang, C.M. Using a photochemical method and chitosan to prepare surface-enhanced Raman scattering-active silver nanoparticles. Anal. Chim. Acta 2012, 729, 1-6. [CrossRef] [PubMed]

6. Rycenga, M.; Cobley, C.M.; Zeng, J.; Li, W.; Moran, C.H.; Zhang, Q.; Qin, D.; Xia, Y. Controlling the synthesis and assembly of silver nanostructures for plasmonic applications. Chem. Rev. 2011, 111, 3669-3712. [CrossRef] [PubMed]

7. Devi, L.B.; Mandal, A.B. Self-assembly of Ag nanoparticles using hydroxypropyl cyclodextrin: Synthesis, characterisation and application for the catalytic reduction of p-nitrophenol. RSC Adv. 2013, 3, 5238-5253. [CrossRef]

8. Cai, Y.K.; Gao, K.L.; Li, G.C.; Deng, Z.J.; Han, G.Z. Facile controlled synthesis of silver particles with high catalytic activity. Colloid Surf. A 2015, 481, 407-412. [CrossRef]

9. Li, P.; Li, S.; Wang, Y.; Zhang, Y.; Han, G.Z. Green synthesis of $\beta$-CD-functionalized monodispersed silver nanoparticles with ehanced catalytic activity. Colloid Surf. A 2017, 520, 26-31. [CrossRef]

10. Xue, C.; Mirkin, C.A. pH- switchable silver nanoprism growth pathways. Angew. Chem. Int. Ed. 2007, 46, 2082-2084. [CrossRef]

11. Sun, Y.; Xia, Y. Shape-controlled synthesis of gold and silver nanoparticles. Science 2002, 298, $2176-2179$. [CrossRef] [PubMed]

12. Ghosh, S.K.; Kundu, S.; Mandal, M.; Nath, S.; Pal, T. Studies on the evolution of silver nanoparticles in micelle by UV-photoactivation. J. Nanopart. Res. 2003, 5, 577-587. [CrossRef]

13. Sintubin, L.; Verstraete, W.; Boon, N. Biologically produced nanosilver: Current state and future perspectives. Biotechnol. Bioeng. 2012, 109, 2422-2436. [CrossRef] [PubMed]

14. Kim, D.; Jeong, S.; Moon, J. Synthesis of silver nanoparticles using the polyol process and the influence of precursor injection. Nanotechnology 2006, 17, 4019-4024. [CrossRef] [PubMed] 
15. Huang, L.; Zhai, M.L.; Long, D.W.; Peng, J.; Xu, L.; Wu, G.Z.; Li, J.Q.; Wei, G.S. UV-induced synthesis, characterization and formation mechanism of silver nanoparticles in alkalic carboxymethylated chitosan solution. J. Nanopart. Res. 2008, 10, 1193-1202. [CrossRef]

16. Maccuspie, R.I. Colloidal stability of silver nanoparticles in biologically relevant conditions. J. Nanopart. Res. 2011, 13, 2893-2908. [CrossRef]

17. Prathna, T.C.; Chandrasekaran, N.; Mukherjee, A. Studies on aggregation behaviour of silver nanoparticles in aqueous matrices: Effect of surface functionalization and matrix composition. Colloid Surf. A 2011, 390, 216-224. [CrossRef]

18. Tejamaya, M.; Römer, I.; Merrifield, R.C.; Lead, J.R. Stability of citrate, PVP, and PEG coated silver nanoparticles in ecotoxicology media. Environ. Sci. Technol. 2012, 46, 7011-7017. [CrossRef] [PubMed]

19. Mallick, K.; Witcomb, M.J.; Scurrell, M.S. Polymer stabilized silver nanoparticles: A photochemical synthesis route. J. Mater. Sci. 2004, 39, 4459-4463. [CrossRef]

20. Krklješ, A.; Nedeljković, J.M.; Kačarević-Popović, Z.M. Fabrication of Ag-PVA hydrogel nanocomposite by $\gamma$-irradiation. Polym. Bull. 2007, 58, 271-279. [CrossRef]

21. Batista, C.C.S.; Albuquerque, L.J.C.; Araujo, I.D.; Albuquerque, B.L.; Silva, F.D.D.; Giacomelli, F.C. Facile synthesis of $1.3 \mathrm{~nm}$ monodispersed Ag nanoclusters in an aqueous solution and their antibacterial activities for E. coli. RSC Adv. 2018, 8, 10873-10882. [CrossRef]

22. Wu, W.; Zhou, T.; Berliner, A.; Banerjee, P.; Zhou, S. Smart core- shell hybrid nanogels with Ag nanoparticle core for cancer cell imaging and gel shell for $\mathrm{pH}$-regulated drug delivery. Chem. Mater. 2010, 22, 1966-1976. [CrossRef]

23. Hu, J.; Zhou, S.; Sun, Y.; Fang, X.; Wu, L. Fabrication, properties and applications of Janus particles. Chem. Soc. Rev. 2012, 41, 4356-4378. [CrossRef] [PubMed]

24. Xu, C.J.; Wang, B.D.; Sun, S.H. Dumbbell-like $\mathrm{Au}-\mathrm{Fe}_{3} \mathrm{O}_{4}$ nanoparticles for target-specific platin delivery. J. Am. Chem. Soc. 2009, 131, 4216-4217. [CrossRef] [PubMed]

25. Wang, F.; Pauletti, G.M.; Wang, J.T.; Zhang, J.M.; Ewing, R.C.; Wang, Y.L.; Shi, D.L. Dual surface-functionalized janus nanocomposites of polystyrene $/ \mathrm{Fe}_{3} \mathrm{O}_{4} @ \mathrm{SiO}_{2}$ for simultaneous tumor cell targeting and stimulus-induced drug release. Adv. Mater. 2013, 25, 3485-3489. [CrossRef] [PubMed]

26. Tran, L.T.C.; Lesieur, S.; Faivre, V. Janus nanoparticles: Materials preparation and recent advances in drug delivery. Expert Opin. Drug Deliv. 2014, 11, 1061-1074. [CrossRef] [PubMed]

27. Chen, L.; Deming, C.P.; Peng, Y.; Hu, P.; Stofan, J.; Chen, S. Gold core@ silver semishell Janus nanoparticles prepared by interfacial etching. Nanoscale 2016, 8, 14565-14572. [CrossRef] [PubMed]

28. Song, Y.; Liu, K.; Chen, S. AgAu bimetallic Janus nanoparticles and their electrocatalytic activity for oxygen reduction in alkaline media. Langmuir 2012, 28, 17143-17152. [CrossRef] [PubMed]

29. Wang, Z.; Chang, Z.; Lu, M.; Shao, D.; Yue, J.; Yang, D.; Li, M.; Dong, W.F. Janus silver/silica nanoplatforms for light-activated liver cancer chemo/photothermal therapy. ACS Appl. Mater. interfaces 2017, 9, 494-496. [CrossRef] [PubMed]

30. Sun, Y.; Chen, M.; Wang, Z.; Wu, L. Facile synthesis of asymmetric Ag-organosilica hybrid nanoparticles with tunable morphologies and optical properties. Chem. Commun. 2014, 50, 5767-5770. [CrossRef] [PubMed]

31. Zha, Z.; Teng, W.; Markle, V.; Dai, Z.; Wu, X. Fabrication of gelatin nanofibrous scaffolds using ethanol/phosphate buffer saline as a benign solvent. Biopolymers 2012, 97, 1026-1036. [CrossRef] [PubMed]

32. Wang, Z.; Zheng, L.; Li, C.; Wu, S.; Xiao, Y. Preparation and antimicrobial activity of sulfopropyl chitosan in an ionic liquid aqueous solution. J. Appl. Polym. Sci. 2017, 134, 44989. [CrossRef]

33. Ayala-Núñez, N.V.; Villegas, H.H.L.; Turrent, L.C.I.; Padila, C.R. Silver nanoparticles toxicity and bactericidal effect against methicillin-resistant Staphylococcus aureus: Nanoscale does matter. Nanobiotechnol 2009, 5, 2-9. [CrossRef]

34. Vukomanović, M.; Pepnik, U.; Zavašnik-Bergant, T.; Kostanjšek, R.; Škapin, S.D.; Suvorov, D. Is nano-silver safe within bioactive hydroxyapatite composites? Acs Biomater. Sci. Eng. 2015, 1, 935-946. [CrossRef]

35. Wen, Y.; Jiang, X.; Yin, G.; Yin, J. Multi-responsive amphiphilic gold nanoparticles (AuNPs) protected by poly (ether amine)(PEA). Chem. Commun. 2009, 43, 6595-6597. [CrossRef] [PubMed]

36. Peng, Y.K.; Liu, C.L.; Chen, H.C.; Chou, S.W.; Tseng, W.H.; Tseng, Y.J.; Kang, C.C.; Hsiao, J.K.; Chou, P.T. Antiferromagnetic iron nanocolloids: A new generation in vivo T 1 MRI contrast agent. J. Am. Chem. Soc. 2013, 135, 18621-18628. [CrossRef] [PubMed] 
37. Chang, E.; Thekkek, N.; Yu, W.W.; Colvin, V.L.; Drezek, R. Evaluation of quantum dot cytotoxicity based on intracellular uptake. Small 2006, 2, 1412-1417. [CrossRef] [PubMed]

38. Tsuchida, E.; Sou, K.; Nakagawa, A.; Sakai, H.; Komastsu, T.; Kobayashi, K. Artificial oxygen carriers, hemoglobin vesicles and albumin- hemes, based on bioconjugate chemistry. Bioconjugate Chem. 2009, 20, 1419-1440. [CrossRef] [PubMed]

39. Scaravelli, R.C.B.; Dazzi, R.L.; Giacomelli, F.C.; Machado, G.; Giacomelli, C.; Schmidt, V. Direct synthesis of coated gold nanoparticles mediated by polymers with amino groups. J. Colloid Interf. Sci. 2013, 397, 114-121. [CrossRef] [PubMed]

40. Batista, C.; Albuquerque, L.; Ribeiro, C.; de Castro, C.; Miranda, E.; Nantes, I.; Albuquerque, B.; Cardoso, M.; Giacomelli, F. Nano-Sized Silver Colloids Produced and Stabilized by Amino-Functionalized Polymers: Polymer Structure-Nanoparticle Features and Polymer Structure-Growth Kinetics Relationships. J. Braz. Chem. Soc. 2017, 28, 1608-1618. [CrossRef]

41. Langille, M.R.; Personick, L.M.; Mirkin, C.A. Plasmon-mediated syntheses of metallic nanostructures. Angew. Chem. Int. Ed. 2013, 52, 13910-13940. [CrossRef] [PubMed]

42. Ye, S.; Song, J.; Tian, Y.L.; Chen, L.C.; Wang, D.; Niu, H.B.; Qu, J.L. Photochemically grown silver nanodecahedra with precise tuning of plasmonic resonance. Nanoscale 2015, 7, 12706-12712. [CrossRef] [PubMed]

43. Yang, L.C.; Lai, Y.S.; Tsai, C.M.; Kong, Y.T.; Lee, C.I.; Huang, C.L. Transformation from silver nanoprisms to nanodecahedra in a temperature-controlled photomediated synthesis. J. Phys. Chem. C 2012, $116,24268-24273$.

44. Romanovskaya, G.I.; Koroleva, M.V.; Zuev, B.K. Photochemical Synthesis of Anisotropic Silver Nanoparticles in Aqueous Solutions in the Presence of Sodium Citrate. Dokl. Chem. 2018, 480, 96-98. [CrossRef]

45. Johnston, H.J.; Hutchison, G.; Christensen, F.M.; Peters, S.; Hankin, S.; Stone, V. A review of the in vivo and in vitro toxicity of silver and gold particulates: Particle attributes and biological mechanisms responsible for the observed toxicity. Crit. Rev. Toxicol. 2010, 40, 328-346. [CrossRef] [PubMed]

46. Hunt, P.R.; Keltner, Z.; Guo, X.; Oldenburg, S.J.; Bushana, P.; Olejnik, N.; Sprando, R.L. Bioactivity of nanosilver in Caenorhabditis elegans: Effects of size, coat, and shape. Toxicol. Rep. 2014, 1, 923-944. [CrossRef] [PubMed]

47. Ahmed, K.B.R.; Nagy, A.M.; Brown, R.P.; Zhang, Q.; Malghan, S.G.; Goering, P.L. Silver nanoparticles: Significance of physicochemical properties and assay interference on the interpretation of in vitro cytotoxicity studies. Toxicol. In Vitro 2017, 38, 179-192. [CrossRef] [PubMed] 